\title{
The Declining Social Significance of Eldercare- A commentary
}

\author{
Ling $\mathrm{Ng} \mathrm{LY}^{*}$ \\ Department of Political Science, University of Victoria, Canada
}

*Corresponding author: Lynn Yu Ling Ng, Department of Political Science, University of Victoria 3800 Finnerty Rd, Victoria, BC V8P 5C2, Canada, Tel: 7785849178; Email: lynnngyuling@uvic.ca

\section{Commentary}

The Covid-19 pandemic has forced an international lockdown. During an indefinite period of heightened anxiety, healthcare workers have emerged as hidden heroes who are the truly essential workers. Yet in the economic blueprints of governments worldwide, the eldercare sector in particular is a missing link in public health concerns. Globally, nursing homes have reported disproportionate death and infection rates compared to any other institutional care setting. In Canada where I now live, long-term care facilities (LTCs) in the provinces of British Columbia, Ontario and Quebec account for up to $82 \%$ of Canada's total deaths [1]. That such alarming statistics are the norm for many countries is perhaps a timely reminder for analysts and researchers, regardless of discipline, to change the severely underrated status of care work.

Doing eldercare responsibly necessarily entails a compromise of the profit maximization imperative. Where this sector of social welfare is concerned, people must come before profit if we are to accept that eldercare work is of a qualitatively different nature compared to other types of socially reproductive work. In the scholarship of Federici $S$, et al. [2], the work of social reproduction refers broadly to the wide range of domestically relevant activities that have traditionally been the domain of unpaid housewives, that is before the internationally mobile female immigrant (in local parlance, the "maid") became available. Compared to 'ordinary' housework - cooking, cleaning, washing and even infant or childcare, eldercare is virtually a labor of love that lies beyond the expectation of monetary remuneration. Keeping apartments clean, preparing healthy meals from scratch and having hygienic environments to reside in are of direct interest to our everyday wellbeing, such that we often do not hesitate to splurge on higher quality equipment that would 'revolutionize our home'. When Federici S, et al. [2] called for the Marxist left movement to notice their missing agenda of eldercare, she was also calling for a redistribution of society's common wealth in that direction. This would require an internal revolution in the hearts and minds of not just but especially professional workers of the younger generation who are used to ageist notions of old age and the value of work. The existing lexicon for older persons is likewise degrading in nature, hence is not conducive to the mental health of senior citizens who have to think of themselves as 'unproductive dependents' and 'fiscal burdens'.

During prolonged periods of quarantine moreover, digital and virtual forms of communication have taken center stage. Yet again, it is the elderly who are the most psychologically isolated since unlike millennials, they were not born into neither did they grow up in an era of ubiquitous internet. In my home country of Singapore, an article in The Straits Times noted that for many senior citizens, making their way to brick-and-mortar stores (despite the increased health risks) would be way more efficient at meeting their needs than trying to figure out online ordering [3].

In general, almost every aspect of change required on the part of individual behavior under pandemic circumstances weighs disproportionately on the elderly, if not in daily social situations then in nursing homes where many spend the remaining years of their lives. Here in Canada, healthcare workers in LTCs and nursing homes are not included in the Canada Health Act since eldercare provision is not formally recognized as a public industry. Numerous studies have shown, woefully but unsurprisingly, that private operators consistently provide an inferior quality of care Stall NM, et al. [4]. The residents and staff of private homes regularly report higher rates of abuse, mistreatment and deplorable living conditions. Both the precarious employment conditions of healthcare workers and the normalized ageism of their care recipients require drastic reform if the sorry plight of eldercare is to improve. 
As part of emergency response plans to Covid-19, governments worldwide have implemented special provisions for healthcare workers to remain in single facilities to minimize unnecessary contact. In Canada, the province of British Columbia was the first to enact a singlesite order and include all healthcare workers under the national Public Health Order [5]. Incentives were given to facility managers to arrange for part-time shift workers to take on full-time schedules so that transferring between multiple facilities was no longer necessary. Minimum wages as determined by labor union standards are also ensured for all healthcare workers where previously it varied according to a nine-step scale, with more junior ranks of nurses earning below living wage.

These welcome changes in the treatment of healthcare workers have been observed to some degree universally as governments are forced to confront the question of public health infrastructure. Still, these adjustments should have been made a normalized state of affairs long ago as countless grassroots activists have long been at pains to advocate, instead of stopping short at being a temporary part of Covid-19. For a large number of elderly people, the benefits of longer life expectancies are increasingly being overridden by pessimistic prospects of abandonment, loneliness and social vulnerability. Eldercare is a blind spot in the societal chase for a good life, because this sector requires us, to put it bluntly, to simply slow down. The theme of marginalized populations has exploded with Covid-19 as it has become obvious that pandemics are not equalizers but exacerbators of socioeconomic inequality. The quality of care depends primarily on the welfare of its caregivers, many of whom are migrant workers with precarious legal statuses and unfair working conditions. Everyone's turn will come, so the question of aging in a post-pandemic world is as important as restoring some elements of basic equality for frontline care providers.

\section{References}

1. MacCharles T (2020) 82\% of Canada's COVID-19 Deaths Have Been in Long-Term Care, New Data Reveals. The Star.

2. Federici S (2012) Revolution at Point Zero: Housework, Reproduction, and Feminist Struggle. USA: PM Press, pp: 208.

3. Tai J (2020) Coronavirus: elderly hit hard by social isolation amid circuit breaker measures. The Straits Times.

4. Stall NM, Jones A, Brown KA, Rochon PA, Costa AP (2020) For-profit long-term care homes and the risk of COVID-19 outbreaks and resident deaths. CMAJ 192(33): 946-955.

5. Longhurst A, Strauss K (2020) Time to end profit-making in seniors' care. Policynote.

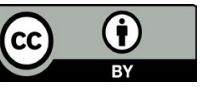

